\title{
Relationship between MT1 melatonin receptor gene polymorphism and seasonal physiological responses in Île-de-France ewes
}

\author{
Xochitl HeRnANDEZ ${ }^{\mathrm{a}, \mathrm{c}}$, Loys Bodin ${ }^{\mathrm{b}}$, Didier CHESNEAU ${ }^{\mathrm{a}}$, \\ Daniel GuILlaUme ${ }^{\mathrm{a}}$, Daniel AllaIN ${ }^{\mathrm{b}}$, Philippe CHEMINEAU ${ }^{\mathrm{a}}$, \\ Benoît MALPAUX ${ }^{\mathrm{a}}$, Martine MIGAUD ${ }^{\mathrm{a} *}$
}

a UMR INRA-CNRS-Université de Tours, Physiologie de la Reproduction et des Comportements, 37380 Nouzilly, France

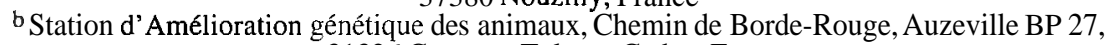
31326 Castanet-Tolosan Cedex, France

c Facultad de Medicina Veterinaria y Zootecnia, Departamento de Reproducción Animal, Universidad Nacional Autonoma de Mexico, Mexico

In the article published in Reprod. Nutr. Dev. 45 (2005) 151-162, the name of Daniel Allain was missing. The complete list of authors should be: Xochitl HERNANDEZ ${ }^{\mathrm{a}, \mathrm{c}}$, Loys BodiN ${ }^{\mathrm{b}}$, Didier Chesneau $^{\mathrm{a}}$, Daniel Gulllaume ${ }^{\mathrm{a}}$, Daniel Allain ${ }^{\mathrm{b}}$, Philippe Chemineau ${ }^{\mathrm{a}}$, Benoît MalpauX ${ }^{\mathrm{a}}$, Martine MIGAUD ${ }^{a *}$.

\footnotetext{
* Corresponding author: migaud@ tours.inra.fr
} 